\title{
Teoria da ação comunicativa e extensão rural
}

\section{Theory of communicative action and rural extension}

\section{Tarcisio Samborski}

tarcisio.samborski@iffarroupilha.edu.br

Agrônomo (UFSM), Mestre em Educação pela UNIJUI e Doutor em Extensão Rural pela UFSM.

\section{Vicente Celestino Pires da Silveira}

vcpsilveira@gmail.com

Professor do Departamento de Extensão Rural e coordenador do Programa de Pós-

Graduação em Extensão Rural - UFSM. Doutor - Universidade de Edinburgh - UK.

\section{Andrea Melissa Mikoski Samborski}

andreasamborski@gmail.com

Mestre em Educação nas Ciências (UNIJUI)- RS. 


\title{
RESUMO
}

O ensaio busca fazer uma leitura da Extensão Rural a partir do referencial teórico de Habermas. Baseado em sua teoria da modernidade aponta-se que as condições que permitiram o difusionismo foram alteradas, dificultando apostas no retorno do mesmo. Já a sua teoria da ação comunicativa, ao permitir compreender melhor a ação extensionista, pode servir para ampliar a comunicação na Extensão Rural.

Palavras-chave: Modernização; diálogo; Habermas; difusão; comunicação

\begin{abstract}
The essay seeks to make a reading of the Rural Extension from the theoretical reference of Habermas. Based on his theory of modernity it is pointed out that the conditions that allowed the diffusionism were altered, making bets on the return of the same difficult. Already his theory of communicative action, by allowing a better understanding of the extensionist action, can serve to broaden the communication in the Rural Extension.
\end{abstract}

Key words: Modernization; dialogue; Habermas; diffusion; communication. 


\section{Introdução}

Aproximar a Teoria da Ação Comunicativa (TAC) da Extensão Rural é possível porque, como a última tem o objetivo de superar os efeitos do difusionismo na ação extensionista, a primeira busca encontrar saídas para os malogros e patologias que a modernização causou. Dessa forma, algumas categorias do construto habermasiano podem ser úteis para compreender a ação extensionista e avançar em relações mais dialógicas na Extensão Rural.

A partir da teoria da modernidade, especialmente a noção de autonomia e da evolução sistêmica, explica-se que as condições históricas que permitiram a constituição de uma extensão rural não estão mais presentes, dificultando uma aposta em velhos métodos difusionistas. Outra seção demonstra que no atual estágio da modernidade, especialmente após a virada linguística ${ }^{1}$, a comunicação se tornou um imperativo na sociedade. Por fim, com a teoria da ação comunicativa apresentamos uma tentativa de melhorar o diálogo e a comunicação na Extensão Rural.

\section{A teoria da modernidade Habermasiana}

Freitag (1993) diz que Habermas busca explicar a gênese da sociedade industrial, diagnosticar suas patologias e apresentar opções para a correção das mesmas. Ele compreende os processos de formação societários como processos coletivos de aprendizagem. Sociedades seriam capazes de aprender, evoluindo de formas simples para arranjos mais complexos, superando as crises e o processo de descentração que ela ocasiona. Segundo ela, Habermas diferencia modernização de modernidade cultural. Entende que a modernização seria o processo de racionalização do Sistema e dos subsistemas econômico e político. Já a modernidade cultural refere-se à modernização do mundo da vida dada a autonomização das esferas de valor como a moral, a ciência e a arte.

Ingram (1994) explica que Habermas defende que a mudança social acontece em dois eixos interdependentes, mas distintos. Um eixo cognitivo e outro moral, com a evolução social se dando através de dois planos: a) utilização progressiva da capacidade de aprendizado dentro da faixa institucional de variação permitida por um determinado

\footnotetext{
${ }^{1} \mathrm{O}$ conceito de virada linguística indica um movimento filosófico do século XX que toma por base a filosofia da linguagem, especialmente a partir de Wittensgein. A popularidade do termo se deu a partir do lançamento por Richard Rorty da antologia “ The linguistic Turn “ em 1966.( Girardhelli Jr,2017).
} 
princípio organizativo e; b) institucionalização progressiva de novos níveis da capacidade de aprendizado, capazes de resolver problemas antigos e também de criar novas dificuldades (INGRAM, 1994, p.160-162).

Habermas entende que sistema e mundo da vida são interdependentes, porém graças ao dinheiro e o poder, os subsistemas econômicos e políticos assumem a supremacia na modernidade, colonizando o mundo da vida. O mundo da vida seria composto pela "experiência comum a todos os atores, da língua, das tradições e da cultura partilhadas por todos. Ele representa aquela vida social cotidiana na qual se reflete o óbvio, aquilo que sempre foi" (FREITAG,1993, p. 26). Em contextos de fala normais, esse óbvio reforça e reafirma a validade normativa, desde que preencha as três pretensões de validade (correção, veracidade e autenticidade) implícitas em qualquer ato linguístico.

Dois aspectos da teoria da modernidade nos importam aqui. A autonomização das esferas do mundo da vida e a complexificação do sistema econômico. Um dos desdobramentos da modernidade foi a autonomia da esfera da ciência e do mundo objetivo. Há uma proliferação de campos de conhecimento específicos, geralmente definidos a partir do objeto a que se dedicam ou da especificidade que abordam. Quando esses conhecimentos passam a ter aplicabilidade, acabam criando especificidades profissionais que se utilizam do conhecimento científico para atuar sobre um determinado mundo objetivo e social, ampliando e complexificando a sociedade. No caso da extensão rural essa autonomia foi fundamental para a institucionalização do " ethos difusionista" e a consolidação de uma ação teleológica baseada na racionalidade instrumental. Como bem afirma Dias "esse seria [...] o poder do ethos estabelecido durante o período do difusionismo produtivista. Foi naquele período que a ação extensionista construiu e estabeleceu seu sentido de ser" (2007, p. 14).

A Extensão Rural autonomizou-se baseada na legitimidade que o discurso científico encontrava na modernidade. Apesar do discurso e talvez até da crença de muitos técnicos, a prática extensionista não era baseada apenas na ciência. Não nos interessa agora, mas a ação extensionista revestida do discurso tecnocrata utilizava a ciência e a técnica como ideologia. Entretanto, outro componente pouco lembrado do período é seu aspecto normativo.

O extensionista executava uma ação teleológica baseada em uma racionalidade que se colocava como a única, já que era baseada na ciência e em saberes adquiridos e legitimados pelo sistema de ensino ao longo da sua formação. Entretanto, não podemos 
esquecer que havia poucas dúvidas do ponto de vista moral no seguimento das normas ou, mesmo que houvesse, não havia condições concretas de não cumpri-las, pelo elevado risco que apresentavam as dissidências no período. São daqueles casos que o modelo de ação não permite o questionamento da norma. Ela é. Cumpra-se.

Assim, se o extensionista estava fazendo o que julgava correto segundo as normas da empresa e da legalidade vigente, também era uma intervenção verdadeira, porque era eficiente frente aos problemas que se dedicava e, do ponto de vista pessoal, ele acreditava nessa solução porque a formação recebida garantia-lhe essa veracidade.

Essas certezas caíram por terra. Hoje os questionamentos da ciência como verdade última e da modernidade são imensos. A modernidade e seu progresso perderam a unanimidade, e em um ambiente democrático publicizam-se posições antes caladas. Há um conjunto de movimentos sociais rurais que questionam a modernização, algo que não foi possível na ditadura militar. Se juntarmos a isso o fato que os agricultores modernizados integrados aos mercados (evolução sistêmica) já não se encontram entre os públicos atendidos pela Extensão Rural e recebem assistência privada, fica difícil imaginar um retorno a uma Extensão Rural nos moldes difusionistas.

Entendemos que desde o movimento do Repensar a Extensão Rural no Brasil encontra-se em situação de contestação e busca de novos rumos, e o conhecimento acumulado pode trazer respostas que vão além do retorno ao passado. Outro fato importante é o questionamento das relações sujeito-objeto e a ascensão do papel da linguagem e da comunicação nas ciências, como veremos a seguir.

\section{A teoria da ação comunicativa}

Baseando-se na análise da relação entre três componentes estruturais [cultura, sociedade e personalidades] e três processos de reprodução [reprodução cultural, integração cultural e socialização], Habermas tenta estabelecer mediações e superar a forma de confronto direto entre a consciência dos indivíduos com os mecanismos de integração social (HABERMAS, 2012, p. 259, 688).

Habermas (2012a e 2012 b) tenta fundamentar os pressupostos ontológicos de quatro conceitos de ação relevantes para a formação da teoria social, analisando as implicações da racionalidade entre ator e mundo. A relação entre a ação e o mundo é fundamental para a expressão da racionalidade conforme se verá adiante. Para o autor em questão, dentro da grande variedade de conceitos de ação que são utilizados pelas Ciências Sociais, é possível defini-los em torno de quatro conceitos básicos: 
a) $\mathrm{O}$ conceito de agir teleológico, central na filosofia da ação, em que o ator

realiza um propósito ou ocasiona o início de um estado almejado, à medida que escolhe em dada situação meios auspiciosos, para então empregá-los de modo adequado. O conceito central é o da decisão entre alternativas voltadas à realização de um propósito, derivada de máximas e apoiada em uma interpretação da situação (HABERMAS, 2012a, p. 163).

Observa-se que há a possibilidade de um agir teleológico de forma individual, sem a necessidade de uma interação. Quando esse ator estabelece relações com outros atores e inclui um cálculo de êxito para a expectativa de suas decisões, surge uma ação estratégica. $\mathrm{O}$ ator faz escolhas e calcula meios e fins para sua ação a partir das expectativas de proveito que espera obter com a mesma (HABERMAS, 2012a, p.164).

b) O agir regulado por normas é uma ampliação do ator individual, implica interação e o pertencimento a um grupo social. No grupo ele

segue uma norma (ou colide com ela), tão logo as condições se apresentam em uma dada situação na qual possa empregá-la. As normas expressam o comum acordo subsistente em um grupo social. Todos os membros de um grupo em que vale determinada norma podem esperar um dos outros que cada um execute ou omita as ações preceituadas de acordo com determinadas situações (Habermas, 2012a, p.164).

A norma cria no grupo social uma expectativa de comportamento generalizado. Porém, ela não tem um sentido cognitivo da expectativa de um acontecimento prognosticado, mas o sentido normativo de que o ator participante em determinado grupo possa usufruir o direito à expectativa de um comportamento (HABERMAS, 2012a).

c) O agir dramatúrgico serviria para descrever interações fenomenologicamente orientadas e carece de uma teoria mais generalizante. Se dá quando os participantes de uma interação constituem um público entre eles e para o qual se apresentam. Nesse contexto, "o ator suscita em seu público uma determinada imagem, uma impressão de si mesmo ao desvelar sua subjetividade em maior ou menor medida" (HABERMAS, 2012a, p. 165).

Por fim, o conceito de agir comunicativo que é aquele que embasa toda a TAC e

refere-se à interação de pelo menos dois sujeitos capazes de falar e agir que estabeleçam uma relação interpessoal (seja com meios verbais ou extraverbais). Os atores buscam um entendimento sobre a situação da ação para, de maneira concordante, coordenar seus planos de ação e, com isso, suas ações (HABERMAS, 2012a, p.166). 
O agir comunicativo representa uma das ligações possíveis entre atividades orientadas a um fim (agir estratégico ou teleológico) e o agir orientado pelo entendimento, sendo que esses dois tipos elementares de ação são irredutíveis um ao outro. No agir comunicativo, há uma possibilidade de resolver o problema da coordenação de ação que surge a partir do momento em que o ator só pode executar o seu plano de ação de modo interativo, com o auxílio ou omissão de pelo menos outro ator. Esse é o caso da maioria das situações em que atua a Extensão Rural. Há certa confusão entre agir comunicativo com o agir estratégico, porém

o agir comunicativo distingue-se, pois, do estratégico, uma vez que a coordenação bem sucedida da ação não está apoiada na racionalidade teleológica dos planos individuais de ação, mas na força racionalmente motivadora de atos de entendimento, portanto, numa racionalidade que se manifesta nas condições requeridas para um acordo obtido comunicativamente (HABERMAS, 1990, p. 72, grifos nossos).

É certo que no agir comunicativo as cadeias de ações dos atores singulares, estruturadas teleologicamente, atravessam os processos de entendimento. Porém, para a coordenação surtir efeito, é preciso uma mudança de perspectiva, abandonando o enfoque objetivador de um agente orientado pelo sucesso, que deseja produzir algo no mundo, pelo enfoque performativo de um falante que busca se entender com outro sobre algo no mundo.

Essa mudança implica em aceitar que existe uma racionalidade que permita a realização de um julgamento objetivo de determinada ação, fato que obriga a uma análise da existência de racionalidade em cada modo de ação.

\section{Comunicação equiparada a interpretação}

A Teoria da Ação Comunicativa (TAC) é uma teoria reconstrutiva que absorve a contribuição de vários autores para explicar como o mundo rompe com os aguilhões do sagrado e instaura uma racionalidade mundana que permite a modernidade, a construção da filosofia da consciência e a virada linguística. Sobre essa última, Habermas (2004) edifica sua obra, pois entende que a filosofia deu primazia à representação, priorizou o interior em relação ao exterior, a imediação da subjetividade em relação à mediação discursiva. Porém, queixa-se que, mesmo após a virada linguística, a comunicação deveria ter sido equiparada com a representação, pois para ele "uma pessoa entende-se 
com outra sobre alguma coisa no mundo. Como representação e como ato comunicativo, o proferimento linguístico aponta em duas direções ao mesmo tempo: o mundo e o destinatário" (HABERMAS, 2004, p. 9).

A linguagem é um veículo do pensamento e também um instrumento de comunicação. Não há possibilidade de que uma concepção ou conceito, mesmo que solipsisticamente obtido, seja partilhado de outra forma que não pela comunicação. Somente uma comunicação bem sucedida permite que a representação dos fatos seja reconhecida e tenha sua validade assegurada entre os participantes da interação.

Tendo isso como princípio, pode-se afirmar que a assimilação da objetividade da experiência estaria ligada à intersubjetividade do entendimento mútuo e que há um "fato transcendental" que permite uma perspectiva evolutiva já que

Deixando afetar-se por razões, sujeitos capazes de falar e agir podem aprender - a mais longo prazo, "não podem não aprender" - Eles aprendem tanto na dimensão cognitivo-moral de suas interrelações como na dimensão cognitiva de seu trato com o mundo (HABERMAS, 2004, p.16).

Essa concepção de aprendizagem derivada da interação, de uma inevitabilidade do "acúmulo do conhecimento" entre os participantes, pressupõe outros desdobramentos como o surgimento da normatividade e da racionalidade. Habermas expressa que "sujeitos capazes de falar e agir, enredados em práticas comunicativas, não podem evitar, em seus pensamentos e ações, regular-se por normas e deixar-se afetar por razões" (HABERMAS,2004, p.32). Para não ser acusado de subjetivista, é preciso aliar a essa condição universal baseada na intersubjetividade, um naturalismo fraco, expresso em um modelo pragmático que seria "um processo de conhecimento é representado como um comportamento inteligente que resolve problemas e possibilita processos de aprendizagem, corrige erros e invalida objeções” (HABERMAS, 2004, p. 34).

Habermas (2004) explica que nessa concepção a função representativa da linguagem não está posta pela clássica formulação de" espelho da natureza", como se o pensamento representasse objetos de forma estática entre o que enuncia e aquilo que é enunciado. A representação, nesses casos, está ligada à comunicação que se dá na dinâmica do crescimento do saber pela solução de problemas e das decepções em lidar com os riscos do mundo circundante e pela justificação das soluções de problemas frente aos outros participantes da argumentação. A capacidade de resolver problemas se dá de maneira crescente, em processos cognitivos de adaptação, construção e seleção que 
dotariam os humanos de uma capacidade resolutiva descoberta sob as limitações que a realidade impõe, realidade que independe da linguagem e impõe limites à nossa prática e que "ela não se faz notar senão performativamente pelas limitações a que estão submetidas nossas soluções de problemas e nossos processos de aprendizado - ou seja, como a totalidade das resistências processadas e das previstas" (HABERMAS, 2004, p. $35)$.

Esse realismo pressupõe que há um mundo objetivo e ele é intersubjetivamente acessível. O real enquanto resistência à ação é conciliado com a premissa epistêmica de um mundo da vida articulado pela linguagem e do qual não se pode fugir. Forma-se assim uma dinâmica que explica o ato linguístico proferido em relação ao mundo objetivo, mundo social (intersubjetivo) e subjetivo (consciência do participante). O início do conhecimento situa-se nos sujeitos providos de faculdades de fala e ação (competência comunicativa) que, ao buscarem um conhecimento de algo no mundo, já se encontram preliminarmente em uma situação na qual predominam relações intersubjetivas que tornam possível um entendimento entre eles.

\section{As possibilidades de racionalidade em cada modo de agir}

Em termos de racionalidade da ação, Habermas afirma que aparentemente apenas o conceito de agir teleológico disponibiliza um ponto de vista que permite o planejamento, cumprimento e julgamento das ações sob a forma de um raciocínio prático e sob bases racionais. Os outros modelos aparentam não permitem a racionalização. Porém, ao se buscar os pressupostos ontológicos que estão ligados a esses modelos de ação, vê-se que existem implicações racionais complexas e intensas.

No agir teleológico, dá-se uma relação entre o ator e um mundo objetivo, formado pelo estado de coisas existentes que são o conjunto daquilo que existe, pode existir ou ser criada por intervenção teleológica. Há um complexo cognitivo-volitivo que permite ao agente fazer uma mediação de suas percepções e formar com elas uma opinião sobre um estado de coisas existentes, estabelecer intenções que visam dar materialidade e realizar um estado de coisas desejadas. Essas opiniões e intenções estabelecem duas relações racionais, pois são acessíveis a um julgamento objetivo com o mundo. Em primeiro, porque é passível avaliar sobre o êxito do ator em fazer concordar suas opiniões e intenções com aquilo que é o caso no mundo e, em segundo lugar, julgar sobre seu êxito nessa concordância entre o que é o caso no mundo com suas opiniões e intenções . É possível julgar suas opiniões e intenções sobre o mundo objetivo ou avaliar o mundo 
objetivo de acordo com suas opiniões ou intenções, se elas estão adequadas ou inadequadas. As externações que o ator teleológico cria em seu agir podem ser julgadas segundo critérios de verdade ou eficácia. A relação do ator com o mundo objetivo inclui também a performance de outros atores que influenciam e são influenciados pelas decisões do ator em questão (agir estratégico) (HABERMAS, 2012a).

$\mathrm{O}$ agir regulado por normas pressupõe a relação entre um ator e dois mundos: o objetivo e o social. "O mundo social é um contexto normativo que estabelece quais interações pertencem ao conjunto de relações interpessoais justificadas" (HABERMAS, 2012a, p. 170). No modelo de ação normativo, os atores possuem um complexo cognitivo que permite um comportamento objetivador para distinção das condições e meios que possui, mas também um complexo motivacional que possibilita um comportamento adequado às normas. Esses dois complexos estão vinculados a um processo de aprendizagem da internalização de valores.

Desta forma, o ator pode ter sua ação julgada de forma objetiva, caso ela esteja de acordo com o contexto normativo reconhecido como legítimo ou desviou-se dela? Além do julgamento da ação, pode-se julgar a legitimidade das normas, questionando se ela representa os interesses dos atingidos, se é possível reconhecê-las como legítimas e se elas podem ser justificadas. Há racionalidade nesse agir porque

o modelo de ação normativo parte do pressuposto de que os envolvidos podem assumir um posicionamento objetivador diante do que é o caso ou do que não é o caso, bem como um posicionamento adequado às normas em face do que (com ou sem razão) lhes é ordenado (HABERMAS, 2012a, p.174).

No caso do agir dramatúrgico, há a necessidade de o ator apresentar uma visão de si mesmo, relacionar-se com o seu mundo subjetivo, concebido como as sentenças vivenciais externadas com veracidade pelo ator. Outras expressões do agir dramatúrgico podem ser julgadas como agir orientado por normas ou mesmo objetivo, como por

exemplo, uma opinião em relação às normas ou sobre um fato. (HABERMAS, 2012a, p. 178-182).

A racionalidade do agir comunicativo deve ser diferenciada dos outros modelos de ação pela forma como a linguagem é utilizada. Nos outros modelos de ação, a utilização da linguagem se dá de forma unilateral. No modelo teleológico, a linguagem é 
um entre muitos media utilizados pelos atores para influenciar os outros. No agir normativo, a linguagem é um medium que transmite valores culturais e no modelo dramatúrgico um medium de autoencenação. No agir comunicativo, a linguagem é um medium de entendimento, em que falantes e ouvintes, a partir do seu mundo da vida previamente interpretado, referem-se a algo no mundo objetivo, social e subjetivo, buscando negociar definições em comum para as situações em que se encontram. No agir teleológico há a expressão do desencadeamento de efeitos perlocutórios (tudo o que é alcançado ou produzido pelo ato de dizer algo); no agir normativo a criação das relações interpessoais e, o agir dramatúrgico expressam vivências de um sujeito. Já a ação comunicativa, em seu ato da fala, expressa uma proposição, a oferta de uma relação interpessoal e uma intenção do falante, ou seja, há uma tripla referência ao mundo objetivo, social e subjetivo (HABERMAS, 2012a, p.182-184).

Essa referência assume funções cognitivas (representação de um estado de coisas), uma função apelativa (exortação dirigidas aos destinatários) e outra expressiva (cientificação de vivências do falante). Nesse processo, o signo linguístico assume a condição de símbolo (pela ordenação a objetos e estados de coisas), de sinal (face ao apelo do ouvinte) e também como sintoma (pela dependência do emissor cuja interioridade ele expressa). Essas referências triplas seriam suficientes para romper a concepção objetivista do entendimento enquanto fluxo de informação entre receptor e emissor (HABERMAS, 2012a, p.478-480).

A diferença da ação comunicativa é que a referência não é mais pontual. Além dessa ampliação, ela está submetida à pretensão de validade que o falante expressa para seu ouvinte. Essa validade é pretensa porque no agir comunicativo ele está sujeito à criticidade do ouvinte sobre aquilo que é proposto. A validade expressa pelo ego, que tem o sentido de verdade (mundo objetivo), correção (mundo social) e veracidade (mundo subjetivo), pode ser julgada pelo alter a partir da integração dessas pretensões em um sistema que comporia uma moldura interpretativa da situação vivida (HABERMAS, 2012a, p. 190-192). Assim, a racionalidade está baseada nesse processo de entendimento

em que as pretensões de validade expressas nos atos de fala são negociadas para a definição da situação em que se encontram e representam um recorte do mundo da vida. Retira-se também a centralidade da ciência e da verdade como único sentido possível de julgamento. Os critérios científicos, as normas, a moral e a leitura que o indivíduo faz de 
seu par na interação são elementos importantes na avaliação de uma situação de ação. Não há mais a primazia da razão técnica instrumental frente aos outros aspectos.

A importância em delimitar esses tipos de ação e as suas racionalidades nasce da questão que persegue Habermas desde o início. Sua teoria da modernidade está baseada na diagnose de que a diferenciação do sistema causa uma complexificação no mundo da vida, implicando muitas vezes em uma forma de colonização desta esfera pelo sistema, causando as patologias sociais. Isso o leva a perguntar se a modernidade capitalista pode ser compreendida como uma racionalização limitada, na qual a ação teleológica e instrumental assumiu a hegemonia frente às outras esferas de ação e racionalidade. Dessa forma, ao buscar resgatar uma racionalidade comunicativa, própria do mundo da vida, busca dar maior amplitude à ação social e recolocar o potencial emancipatório da modernidade, que é negado por muitos.

\section{A ação extensionista e a teoria da ação comunicativa}

A Extensão Rural hoje está sujeita ao jogo de poder e de disputa de projetos na sociedade. Isso atravessa as relações com entidades parceiras e até dentro do corpo funcional. A identidade é alterada, surgem grupos solidários e eles são dinâmicos, alteram-se de acordo com as mudanças no campo do poder. Tudo isso causa incertezas e dúvidas para os extensionistas e sua atuação concreta. O sistema fica mais complexo e restringe a ação. Nesse sentido, a divisão entre sistema e mundo da vida é um artifício interessante na definição de espaços e tempos em que podem ser coordenadas ações entre os extensionistas e a população que atende.

No cotidiano entre extensionistas e aqueles com quem se relacionam, há erros e acertos, idas e vindas pois "as manifestações comunicativas estão inseridas, ao mesmo tempo, em diferentes relações com o mundo" (HABERMAS,2012b, P.221). É esse sistema de referências que forma o pano de fundo da situação em que se dá a comunicação, não sendo ela algo que pode ser delimitado de forma rigorosa, porque elas são envolvidas por um horizonte que é dinâmico, afinal, "a universalidade das estruturas comunicativas [...] consiste num sentido compartilhado que regula a ação, permanecendo dependente das interpretações variadas e flutuantes dos agentes históricos." (INGRAM, 1994, p.229). A situação de ação "se apresenta como uma esfera de necessidades atuais de entendimento e de possibilidades de ação" (HABERMAS,2012b,p.226) e pode ser considerada a unidade empírica por excelência para estudos dos processos de entendimento. 
Nesse contexto situativo, que representa recortes do mundo da vida dos participantes, surgem os atos comunicativos que são passíveis de crítica a partir de três aspectos

Sob o aspecto da correção, que o falante reivindica em favor da sua ação mediante referência a um contexto normativo (ou então, de maneira mediata, em favor dessas próprias normas); sob o aspecto da veracidade, que o falante reivindica em favor da externação de vivências subjetivas a que ele tem acesso privilegiado; e por fim sob o aspecto da verdade, que o falante reivindica com sua externação em favor de um enunciado (ou em favor das suposições de existência do teor de um enunciado nominalizado) (HABERMAS, 2012a, p.531).

Habermas (2012a) afirma que a estrutura interna racional dos processos de entendimento está baseada em quatro elementos: a) três referencias de mundo dos atores (como algo no mundo objetivo, algo no mundo social e algo no mundo subjetivo); b) as pretensões de validade (verdade proposicional, correção normativa e veracidade ou autenticidade); c) o conceito de um comum acordo racionalmente motivado, apoiado no reconhecimento intersubjetivo de pretensões de validade criticáveis e por fim; d) a concepção de entendimento enquanto negociação cooperativa de definições situacionais comuns.

Essa estrutura permite ampliar a compreensão no diálogo e servir de base para uma ação extensionista comunicativa.O simples fato de um extensionista admitir os dois primeiros elementos, reconhecendo outros mundos e outras formas de validade é uma superação da visão objetivista do difusionismo. Compreender que existe racionalidade para além dos conhecimentos obtidos pelo método científico tradicional, pode significar uma conciliação entre o saber técnico e o saber popular, polêmica ainda presente na Extensão Rural. Um benzimento de pragas, que era racional na Idade Média por força das monitórias, é considerado irracional hoje, mas é veraz para o agricultor e pode ser aceito como prática aceitável entre seus vizinhos. O julgamento objetivo do técnico não irá mudar a referência subjetiva que o agricultor tem sobre a prática. Por outro lado, se um agricultor que trabalhe com agroindústria entender o contexto normativo que o extensionista trabalha, não terá dificuldade de aceitar que seu produto seja aceitável para o consumo humano em seu município e impróprio para outros munícipes vizinhos, por mais irracional que isso possa parecer. Como se vê, são contradições que só existem se analisarmos apenas os agricultores que possuem contradições. Outra contribuição potencial da TAC para a Extensão Rural é romper com a abordagem setorial, comum nos 
profissionais das ciências agrárias. Há uma herança de considerar a produção antes do humano. Sou aquilo que produzo. Um olhar voltado para a situação da ação, rompe essa setorialização pois obriga um olhar mais holístico.

Podemos afirmar que hoje a ação teleológica acaba dividindo com a ação normativa as preocupações dos extensionistas. A democratização e alternância no poder da gerência do Estado coloca o aspecto normativo em patamar semelhante ao técnico. $\mathrm{O}$ desafio parece residir no reconhecimento do aspecto subjetivo de sua ação. A autenticidade de um projeto comunicativo de Extensão Rural é aceito como válido pelo extensionista? Sua formação profissional prepara-o para buscar a coordenação de ações cooperadas ou para atingir resultados? Da mesma forma, para que não recaia tudo sobre os extensionistas, as organizações priorizam a construção de relações mais dialógicas entre seus técnicos, entre eles e seu público e também entre as entidades parceiras ou são marcadas por um agir estratégico que prioriza o resultado e dificulta o entendimento?

Uma crítica que poderia surgir sobre essa estrutura de análise é a de que nem sempre é possível estabelecer relações a partir de um agir orientado pelo entendimento. E realmente é verdadeiro. Porém em uma situação ideal de fala persistem relações mais dialógicas, capazes de sustentar ações cooperadas da interação. Esse modelo nos servirá como referência para diagnosticar desvios comunicativos que impeçam a realização do entendimento. Afinal, se a Extensão estiver presente no mundo da vida das pessoas, [fato que todos almejamos], sempre haverá um momento que esse entendimento será necessário.

Pode-se sugerir que há o risco de uso desse referencial para fins estratégicos, ou seja, para ver o outro como objeto e não como sujeito. Sim, existe. Porém, só vai dificultar mais um entendimento futuro, pois não há como manter um consenso sobre bases falsas. Enfim, se for aceito que a necessidade de se entender com os outros é um imperativo, a abordagem da pragmática da linguagem e a intenção reconstrutiva da Teoria da Ação Comunicativa oferece possibilidades para a melhoria da comunicação na ação extensionista.

\section{Referências bibliográficas}

DIAS, M. M. As mudanças de direcionamento da Política Nacional de Assistência Técnica e Extensão Rural (Pnater) face ao difusionismo. Revista Oikos, Viçosa, v.18, n. 2, p.11-21, 2007.

FREITAG, Bárbara. Habermas e a filosofia da modernidade. Perspectivas, São Paulo, n. 16, p. 23-45,1993. 
FREITAG, Bárbara; ROUANET, Sérgio Paulo (orgs). Habermas: sociologia. São Paulo: Ática, 1980.

GHIRALDELLI JR, P. Virada Linguística - um verbete. Disponível em https://ghiraldelli.files.wordpress.com/2008/07/virada.pdf acesso em 28/10/2017.

HABERMAS, J. Pensamento pós metafísico: estudos filosóficos. Rio de Janeiro: Tempo Brasileiro, 1990.

Verdade e Justificação: ensaios filosóficos. São Paulo: Loyola, 2004.

Teoria do agir comunicativo, 1: racionalidade de ação e realização social. São Paulo: Editora WWF Martins Fontes, 2012a.

. Teoria do agir Comunicativo, 2: sobre a crítica da razão funcionalista. São Paulo: Editora WWF Martins Fontes, 2012b.

INGRAM, David. Habermas e a Dialética da Razão. 2a ed. Brasília: Ed.UnB, 1994. 